\title{
Multilineage Dysplasia as Assessed by Immunophenotype in Acute Myeloid Leukemia: A Prognostic Tool in a Genetically Undefined Category
}

\author{
Francesco Mannelli ${ }^{1,2, *(D)}$, Sara Bencini ${ }^{1,3}$, Matteo Piccini ${ }^{1}$, Giacomo Gianfaldoni ${ }^{1}$, \\ Maria Ida Bonetti 1,3, Benedetta Peruzzi ${ }^{3}$, Roberto Caporale ${ }^{3}$, Barbara Scappini ${ }^{1}$, \\ Fabiana Pancani ${ }^{1}$, Vanessa Ponziani ${ }^{1}$, Leonardo Signori ${ }^{1}{ }^{1}$, Michela Zizza ${ }^{1}$, \\ Francesco Annunziato ${ }^{3}$ and Alberto Bosi ${ }^{1}$ \\ 1 Struttura Operativa Dipartimentale Ematologia, Azienda Ospedaliero-Universitaria Careggi, 50134 Firenze, \\ Italy; sarabencini1179@gmail.com (S.B.); piccinim@aou-careggi.toscana.it (M.P.); \\ gianfaldonig@aou-careggi.toscana.it (G.G.); marida.bonetti@gmail.com (M.I.B.); \\ scappinib@aou-careggi.toscana.it (B.S.); fabianapancani@virgilio.it (F.P.); \\ vanessa.ponziani@uslnordovest.toscana.it (V.P.); leonardo.signori@unifi.it (L.S.); \\ michela.zizza@unifi.it (M.Z.); alberto.bosi@unifi.it (A.B.) \\ 2 Centro Ricerca e Innovazione Malattie Mieloproliferative (CRIMM), AOU Careggi, 50134 Firenze, Italy \\ 3 Centro Diagnostico di Citofluorimetria e Immunoterapia, AOU Careggi, 50134 Firenze, Italy; \\ peruzzib@aou-careggi.toscana.it (B.P.); caporaler@aou-careggi.toscana.it (R.C.); \\ francesco.annunziato@unifi.it (F.A.) \\ * Correspondence: francesco.mannelli@unifi.it; Tel./Fax: +39-055-7947824
}

Received: 30 September 2020; Accepted: 27 October 2020; Published: 30 October 2020

check for updates

Simple Summary: The prognostic role of multi-lineage dysplasia is still debated in acute myeloid leukemia. The aim of our work was to study dysplasia by a technique alternative to the conventional morphological method, which is multi-parameter flow cytometry. To this end, we used an immunephenotypic score (IPS), able to estimate dysplasia by the extent of deviation from normal profile, obtained in a control group. IPS provided no insight into prognosis when considered overall nor within well-defined genetic categories. Of interest, IPS-related dysplasia conveyed significant prognostic information when we focused on genetically undefined patients, triple-negative for NPM1, FLT3 and CEBPA. This category still represents a non-negligible fraction of patients, that lack specific molecular features either for targeted drugs or for proper risk assessment. In this context, our data could help address the relative unmet needs in treatment strategy, and provide insight into response prediction in the rapidly evolving therapeutic scenario of AML.

Abstract: Acute myeloid leukemia (AML) "with myelodysplasia-related changes (MRC)" is considered a separate entity by the World Health Organization (WHO) classification of myeloid neoplasms. While anamnestic and cytogenetic criteria provide objective attribution to this subset, with clear unfavorable prognostic significance, the actual role of multi-lineage dysplasia (MLD) as assessed by morphology is debated. The aim of our work was to study MLD by a technique alternative to morphology, which is multiparameter flow cytometry (MFC), in a large series of 302 AML patients intensively treated at our Center. The correlation with morphology we observed in the unselected analysis reiterated the capability of the MFC-based approach at highlighting dysplasia. MLD data, estimated through an immune-phenotypic score (IPS), provided no insight into prognosis when considered overall nor within well-defined genetic categories. Of interest, IPS-related dysplasia conveyed significant prognostic information when we focused on genetically undefined patients, triple-negative for NPM1, FLT3 and CEBPA (TN-AML). In this context, the lack of dysplastic features (IPS_0) correlated with a significantly higher CR rate and longer survival compared to patients 
showing dysplasia in one or both (neutrophil and erythroid) cell lineages. The impact of IPS category maintained its validity after censoring at allogeneic HSCT and in a multivariate analysis including baseline and treatment-related covariates. In a subgroup featured by the lack of genetic determinants, our data could help address the relative unmet needs in terms of risk assessment and treatment strategy, and provide insight into prediction of response in the rapidly evolving therapeutic scenario of AML.

Keywords: acute myeloid leukemia; immunophenotype; multilineage dysplasia; AML with myelodysplasia-related changes

\section{Introduction}

Acute myeloid leukemia (AML) "with myelodysplasia-related changes (MRC)" is considered a separate entity by the World Health Organization (WHO) classification of myeloid neoplasms [1,2]. The attribution to this category would point out the clonal evolution of AML from a previous myeloid disorder, a process that generally indicates an unfavorable prognosis. This can rely on three different criteria: anamnestic (previous diagnosis of myelodysplastic syndrome (MDS) or myeloproliferative neoplasm); cytogenetic (presence of specific karyotype abnormalities); morphological (evidence of multilineage dysplasia (MLD)). Anamnestic and cytogenetic criteria are not usually subject to controversy because of the objectivity of their evaluation and of the clear demonstration of the inherent unfavorable prognosis, which is, in turn, preparatory for an appropriate therapeutic approach [3-5]. Major issues regard AML with MLD, both for its correct classification and its actual prognostic significance. The available literature yields conflicting results, possibly for technical and biological reasons [3-7]. The morphological assessment of residual hematopoiesis at AML diagnosis is primarily flawed by operator-dependency. Its specific application is even more complicated in this setting because residual non-blast cells can be very few at diagnosis. Biologically, MLD might convey insight into a pre-existing clonal hemopoiesis but it could also merely result from pathologic differentiation/maturation by the leukemic clone. Further, the expansion of knowledge about genetic background of AML calls for a reconsideration of MLD role. In well-defined genetic entities, such as AML-bearing NPM1 or CEBPA (bi-allelic) mutations, the role of MLD has been downsized and the therapeutic strategies should not base upon it in this context [8-12]. In less characterized AML subsets, it is still debated if MLD prognostic significance is meaningful enough to support important clinical decisions as the allocation to allogeneic stem cell transplantation (HSCT) [13]. The aim of our work was to study MLD by a technique alternative to morphology, which is multiparameter flow cytometry (MFC), progressively emerging as a useful method to assess dysplasia, particularly in the MDS setting [14-17]. Our rationale was that an MFC-based evaluation could get further insight into MLD's actual significance, especially in distinct genetic subsets.

\section{Patients and Methods}

\subsection{Patients}

Patients entering the study had a diagnosis of untreated non-promyelocytic AML, based on morphological, immunophenotypic, and molecular criteria, and were intensively treated as specified in the Supplemental Data. The study was approved by the local institutional review board (protocol number: 2013/0034874). Written informed consent was obtained from trial patients in accordance with the Declaration of Helsinki. Enrolment criteria required (1) intensive treatment, (2) availability of immunophenotypic data at diagnosis, and (3) signed informed consent. 


\subsection{Morphology}

Morphological revision of AML cases was carried out on bone marrow smears, stained with the May-Grunwald-Giemsa method. Dysplasia was assessed according to WHO [1,2]. The definition of multi-lineage dysplasia (MLD) was based on the presence of dysplasia ( $>50 \%$ of dysplastic cells per lineage) in at least two cell lineages in bone marrow smears. Dysgranulopoiesis was defined as $\geq 50 \%$ of $\geq 10$ polymorphonuclear neutrophils being agranular or hypogranular, or with hyposegmented nuclei (pseudo Pelger-Huet anomaly). At least 25 cells were evaluated, but usually 100 cells were counted. Dyserythropoiesis was defined as $\geq 50 \%$ of dysplastic features in $\geq 25$ erythroid precursors: megaloblastoid aspects, karyorrhexis, nuclear particles, or multinuclearity. Dysmegakaryopoiesis was diagnosed when $\geq 3$ megakaryocytes or $\geq 50 \%$ in $\geq 6$ cells showed dysplastic features such as micromegakaryocytes, multiple separated nuclei, or very large single nuclei.

\subsection{Karyotype}

Cytogenetic analysis was performed on BM cells at diagnosis according to the International System for human Cytogenetic Nomenclature [18]. Cytogenetic risk was defined according to Medical Research Council (MRC) [19].

\subsection{Molecular Genetics}

The presence of the NPM1 mutation was defined by immunohistochemical criteria, that is demonstration of aberrant cytoplasmic expression of NPM1 [20] or by mutational analysis for NPM1 gene mutations [21]. The presence of FLT3 internal tandem duplications (ITD) and Tyrosine Kinase Domain (TKD), and CEBPA mutations were investigated as described [21-23].

\subsection{Flow Cytometry}

In order to assess MLD by immunophenotype, we adapted to AML an approach previously described for MDS [14]: dysplasia was appraised for neutrophil and erythroid compartments through an immuno-phenotypic score (IPS) including 17 parameters (13 for neutrophil and four for erythroid compartment). Cell compartments were considered not assessable for dysplasia when not detectable as at least $0.01 \%$ of total BM cells. For data analysis, Infinicyt (Cytognos SL, Salamanca, Spain) software was used. Technical details were published previously [11] and summarized in the Supplemental File. Briefly, neutrophil and erythroid cell compartments were identified on the basis of forward (FSC) and sideward (SSC) light scatter characteristics and their reactivity for CD45. Parameters included by IPS were expressed as percentage of positive cells for an antigen within a cell compartment and/or its mean fluorescence intensity (MFI; arbitrary relative linear units, scaled from 0 to $10^{4}$, normalized upon a control). A score was attributed to each parameter included in the IPS depending on the extent of deviation from normal phenotypic profile, as defined in parallel in control groups. Single cell lineages of AML cases were considered to be dysplastic when their relative IPS value was higher than mean IPS +2 standard deviations (SD) in controls.

\subsection{Definitions}

Complete remission (CR), non-responsive disease (NR), early induction death (ED), disease-free survival (DFS), and overall survival (OS) were defined according to standard criteria [24]. For risk definition, patients were stratified according to the European Leukemia Net (ELN) 2010 system in post hoc analysis [25].

\subsection{Statistical Aspects}

Pairwise comparisons between patient characteristics were performed using the Mann-Whitney test or the Kruskal-Wallis test for continuous variables and Pearson's chi-squared test or Fisher's exact test for categorical variables. Survival was estimated with the Kaplan-Meier method and 
long-term outcomes were compared with the log-rank test. The Cox proportional-hazards model was applied to estimate hazard ratios with 95\% confidence intervals (CI) for disease-free survival (DFS), i.e., the interval from CR to relapse or death, overall survival (OS), i.e., the interval from study entry to death, and event-free survival (EFS), i.e., the interval from study entry to primary refractory disease, relapse or death, whichever occurs first) in both univariate and multivariate contexts. In order to rule out an impact by allogeneic SCT, we censored patients receiving allogeneic SCT at the date of transplant in a further analysis. All $P$ values were two-sided, and a $5 \%$ significance level was set. Statistical analyses were performed using R version 3.5.0 and SPPS version 26.

\section{Results}

\subsection{Characteristics of Patients and Treatment Flow}

From April 2004 to April 2017, 326 patients affected by AML met the inclusion criteria. Maturing cell compartments were both detectable (i.e., $\geq 0.01 \%$ of global cells) and evaluable for dysplasia in $302(92.6 \%)$ patients. Their clinical and biological characteristics are detailed in Table 1. As per induction treatment, 209 (69.2\%) and 93 (30.8\%) received standard-dose (SDAC) and high-dose cytarabine (HDAC) containing regimen, respectively. The comparison between induction treatment groups did not show any relevant unbalances for main clinical and biological features (Table S1) nor differences in survival estimates (Figure S1). Overall, at the evaluation of responses after first induction course, 182 patients achieved CR (60.2\%), 15 experienced an ED (5.0\%), and 105 were declared NR $(34.8 \%)$. When evaluated after a second chemotherapy course administered to NR patients, the CR rate increased to $76.5 \%(n=231 / 302)$. One-hundred-and-twenty patients received an allogeneic transplant, of whom 88 were in first CR as part of the consolidation phase.

Table 1. Characteristics of patients in the overall cohort.

\begin{tabular}{|c|c|}
\hline & Overall $n=302$ \\
\hline Age, median (range) & $56(18-75)$ \\
\hline WBC, $\times 10^{9} / \mathrm{L}$, median (range) & $13.9(0.6-435.0)$ \\
\hline $\mathrm{Hb}, \mathrm{g} / \mathrm{dL}$, median (range) & $9.0(3.4-14.9)$ \\
\hline Plt, $\times 10^{9} / \mathrm{L}$, median (range) & $50(3-373)$ \\
\hline Bone marrow blasts, $\%$, median (range) & $90(20-100)$ \\
\hline \multicolumn{2}{|l|}{ Karyotype, n (\%) } \\
\hline Favorable & $20(6.6)$ \\
\hline$t(8 ; 21) / R U N X 1-R U N X 1 T 1$ & $11(3.6)$ \\
\hline inv(16)/CBF-MYH11 & $9(3.0)$ \\
\hline Normal & $174(57.6)$ \\
\hline Intermediate, non-normal & $31(10.3)$ \\
\hline Adverse & $58(19.2)$ \\
\hline complex & $38(12.6)$ \\
\hline chromosomes 5/7 abnormalities & $14(4.6)$ \\
\hline chromosome 3 abnormalities & $4(1.3)$ \\
\hline$t(6 ; 9)$ & $2(0.7)$ \\
\hline Lack of growth & $19(6.3)$ \\
\hline
\end{tabular}


Table 1. Cont.

\begin{tabular}{lc}
\hline \multicolumn{2}{l}{ Overall $\mathrm{n}=302$} \\
\hline Molecular genetics, $\mathbf{n}(\mathbf{\%})$ & $115(38.0)$ \\
\hline NPM1-mutated & $73(24.2)$ \\
\hline FLT3-ITD & $7(2.3)$ \\
\hline FLT3-TKD & $13(4.3)$ \\
\hline CEBPA-DM & $146(48.3)$ \\
\hline WHO Classification, $\mathbf{n}(\%)$ & $4(1.3)$ \\
\hline Recurrent genetic abnormalities & $75(24.8)$ \\
\hline Therapy-related & $77(25.6)$ \\
\hline Myelodisplasia-related changes & $90(29.8)$ \\
\hline ELN 2010 risk groups, $\mathbf{n}(\%)$ & $129(42.7)$ \\
\hline Favorable & $25(8.3)$ \\
\hline Intermediate-1 & $58(19.2)$ \\
\hline Intermediate-2
\end{tabular}

Differences between treatment groups were evaluated using Mann-Whitney test for continuous variables and Fisher exact tests or $\chi^{2}$ for categorical variables. Values in bold are statistically significant $(p<0.05)$. Abbreviations: WBC, white blood cells; $\mathrm{Hb}$, hemoglobin, Plt, platelets; CEBPA-DM: double-mutated; ELN, European Leukemia Net.

\subsection{Study of MLD by Immuno-Phenotype}

The median IPS in the overall cohort was 3.5 (range 0.0-13.5), as the result of the sum of phenotypic score in neutrophil (median $2.0(0.0-10.5))$ and erythroid $(1.0(0.0-5.0))$ lineage in individual cases. We explored the distribution of IPS values according to morphological findings: a parallel trend was observed between IPS values and the number of dysplastic cell lineages as stratified by morphology (Figure 1A). Median phenotypic scores in single lineage (neutrophil or erythroid) were higher when the same lineage was judged as dysplastic at morphology (Figure S2); the trend was not significant for erythroid cells, possibly because of a narrower range of variability. When investigated across different AML sub-classifications, non-significant trends toward higher median IPS values were observed for adverse karyotype, CEBPA-DM and WHO-defined MRC (Figure 1B,C and Figure S3). Within the latter group, the distinction between MDS-related cytogenetic abnormalities versus morphologically-assessed MLD did not show any relevant difference in IPS (Figure 1D). A limited sample size $(n=4)$ must be acknowledged for the range of values in tAML. Based on normal ranges defined in the control group, $74(24.5 \%)$ patients showed both cell lineages as phenotypically normal (IPS_0), whereas 133 (44.0\%) and 95 (31.5\%) had one (IPS_1) and two (IPS_2) dysplastic lineages, respectively. No significant clinical-biological difference emerged from the comparison of these three groups, including their distribution in selected WHO- and genetically defined categories, except for a lower platelet count in IPS_1 and IPS-2 categories (Table S2). 

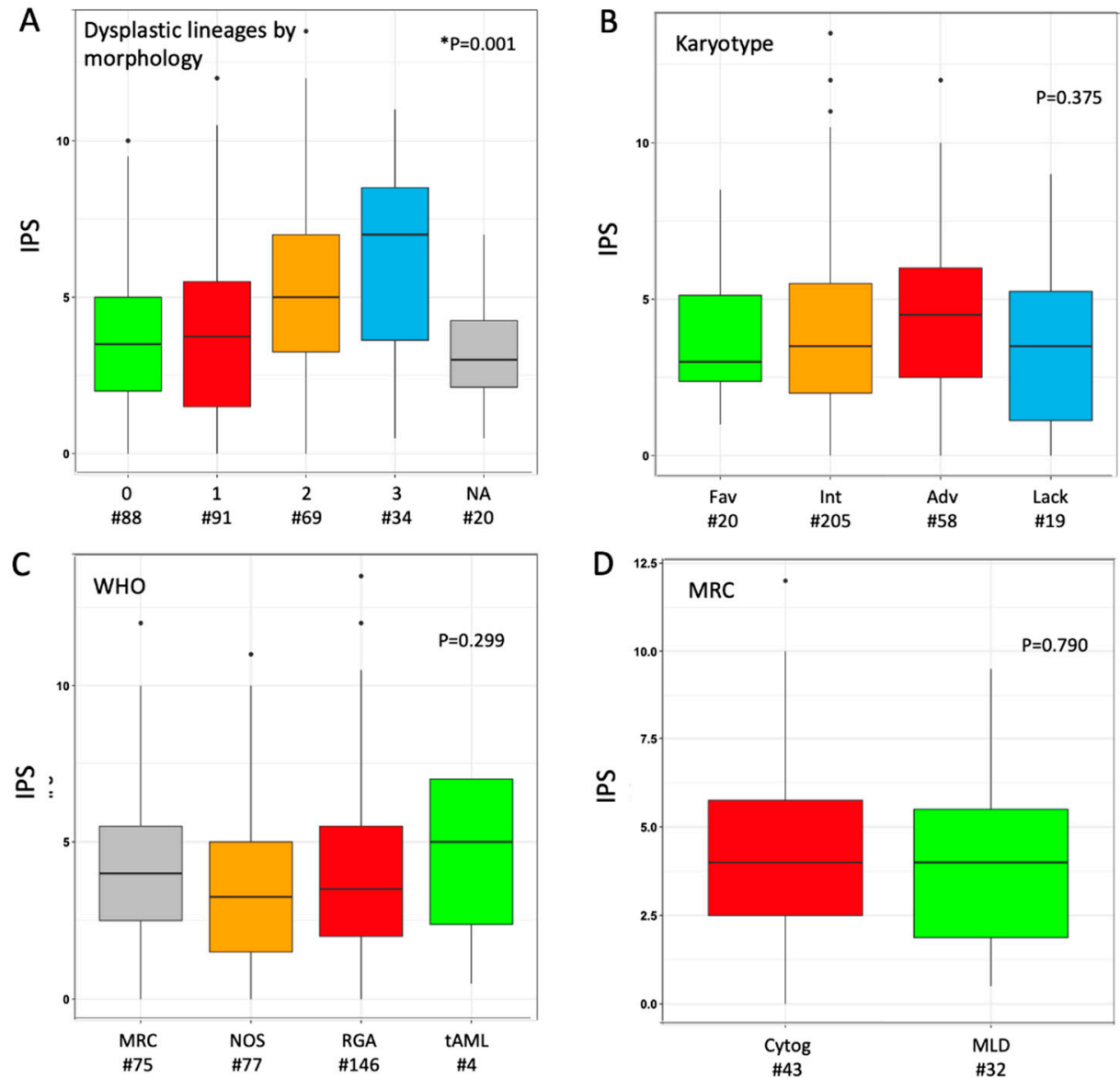

Figure 1. Distribution of immunophenotypic score (IPS) according to disease categorization. Box plot diagrams display the distribution of IPS values according to (A) number of dysplastic cell lineages by morphology, (B) karyotype risk, (C) WHO subset, (D) criterion for assignment to AML-MRC (either cytogenetic or morphological). Boxes represent the interquartile range that contains $50 \%$ of the cases, the horizontal line in the box marks the median. Dots are outliers. Comparisons were carried out by Mann-Whitney or Kruskal-Wallis or test (depending on number of categories, either two or more). * In panel (A), twenty cases were not assessable (NA) for any of the three cell lineages by morphology; in this analysis, Kruskal-Wallis test was carried out excluding NA cases. Abbreviations: IPS, immune-phenotypic score; Fav, favorable; Int, intermediate; Adv, adverse; Lack, lack of growth; WHO, World Health Organization; MRC, myelodysplasia-related changes; NOS, not otherwise specified; RGA, recurrent genetic abnormalities; tAML, therapy-related AML; Cytog, defined by MDS-related cytogenetic abnormality; MLD, defined by multilineage dysplasia at morphology; wt, wild type; MUT, mutated; ITD, internal tandem duplication; DM, double-mutated.

\subsection{Correlation with Outcome in the Overall Cohort and within Selected Subgroups}

The single-course CR rate was $64.9 \%(n=48 / 74), 54.9 \%(n=73 / 133)$ and $64.2 \%(n=61 / 95)$ in IPS_0, IPS_1 and IPS_2, respectively $(p=0.956)$. After a second cycle, CR rate increased up to $83.8 \%$ $(n=62 / 74), 70.7 \%(n=94 / 133)$ and $78.9 \%(n=75 / 95)$ in IPS_0, IPS_1 and IPS_2, respectively $(p=0.576)$. We then assessed whether IPS results affected the risk of relapse and survival estimates. No significant effect by IPS was observed on outcome as assessed by DFS, OS or EFS in the overall cohort (Figure 2). In the analysis of OS, a non-significant trend toward better outcome was observed for IPS_0 patients (in single comparisons, $p=0.083$ and $p=0.024$ versus IPS_1 and IPS_2, respectively). We searched for any interaction of IPS and prognosis within WHO- and genetically defined disease subsets. IPS did not show a significant prognostic impact in AML with recurrent genetic abnormalities (RGA) nor in AML-MRC (Figures S4 and S5). Within non-otherwise-specified (NOS) AML, a trend for longer survival 
emerged in IPS_0 patients, reaching statistical significance for EFS (Figure S6). IPS did not correlate with survival in cytogenetic categories (favorable, intermediate, adverse), nor in NPM1-mutated and FLT3-ITD subgroups (Figures S7-S11).

A
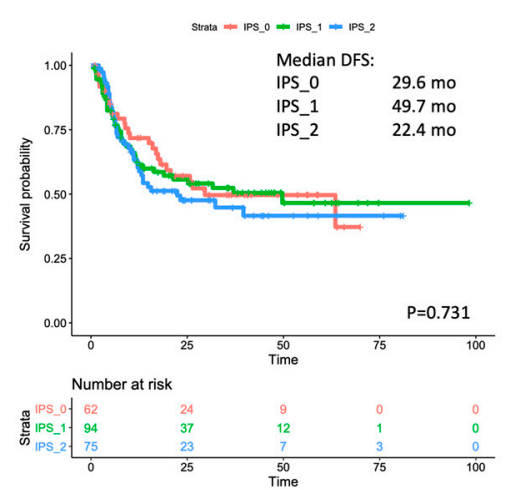
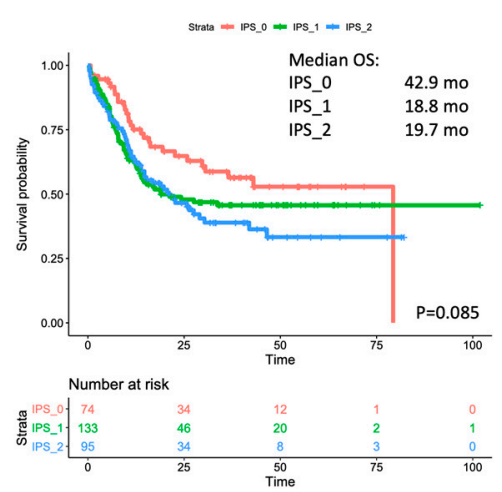

C

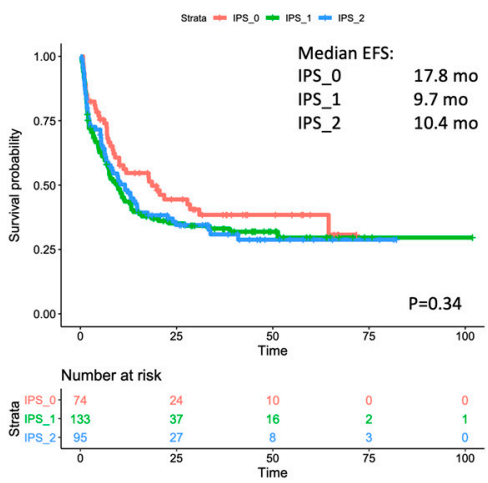

Figure 2. Survival estimates according to IPS in the overall cohort. Major outcomes as assessed by Kaplan-Meier curves for (A) disease-free survival (DFS), (B) overall survival (OS), and (C) event-free survival (EFS) according to number of dysplastic cell lineages by immunophenotypic score (IPS). The curves of patients with no dysplastic lineages (IP_0) are depicted in red; the curves of patients with one dysplastic lineage (IPS_1) are depicted in green, and the curves of patients with both (neutrophil and erythroid) dysplastic lineages (IPS_2) are depicted in blue. Median survival estimates are reported in months. $p$ values were calculated through the log-rank test.

\subsection{Correlation with Outcome in the Triple-Negative Subset}

An impact on prognosis emerged when we focused on genetically undefined patients, that means with intermediate-risk or lack of growth karyotype, and triple-negative for NPM1, FLT3-ITD and CEBPA (TN-AML). The survival curves showed a parallel trend between IPS and prognosis: the higher was the number of dysplastic lineages, the shorter was the survival as assessed by DFS, OS, EFS (Figure 3A-C). Since IPS_1 and IPS_2 had very similar survival, these patients were gathered and compared to IPS_0 subgroup in the following analyses. As per baseline characteristics, IPS_0 showed a significantly lower WBC count and incidence of normal karyotype compared to IPS_1-2 (Table 2). Overall CR rate was $90.9 \%(n=20 / 22)$ and $68.9 \%(n=42 / 61)$ in IPS_0 and IPS_1-2, respectively $(p=0.048$, $\mathrm{OR}=4.52 ; 95 \% \mathrm{CI}$ 0.96-21.3). The IPS group affected prognosis, as demonstrated by DFS, OS and EFS (Figure 3D-F). Analogous results were found after censoring at allogeneic HSCT (Figures S12 and S13). Subgroup analysis within TN-AML category confirmed the validity of this result across different clinically and genetically defined subsets (Figure 4 and Figures S14 and S15). Of interest, the presence of multi-lineage dysplasia, as assessed by morphology, did not influence prognosis in this context (Figure S16). In a multivariate model ran in TN-AML subset, that included pre-treatment (age, WBC count, karyotype) and treatment-related (induction regimen, allogeneic transplant) covariates, IPS was the only independent variable associated with OS (HR 3.75; 95\% CI $1.5-9.6 ; p=0.006)$ and an independent variable for DFS (HR 2.2; 95\% CI 0.9-5.5; $p=0.046)$ and EFS (HR $2.50 ; 95 \% 1.2-5.1 ; p=0.012$ ), together with allogeneic transplant (Table 3). In patients achieving CR, an MRD evaluation by MFC was available for 62 patients. MRD negativity rate had a non-significant trend in IPS groups, being $50.0 \%(n=10 / 20)$ and $38.1 \%(n=16 / 42)$ in IPS_0 and IPS_1-2, respectively $(p$ $=0.41)$. 
A
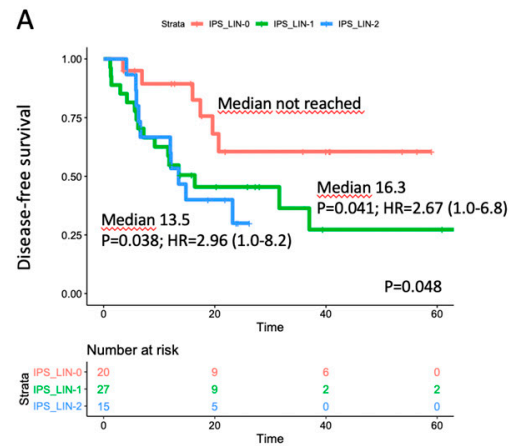

D
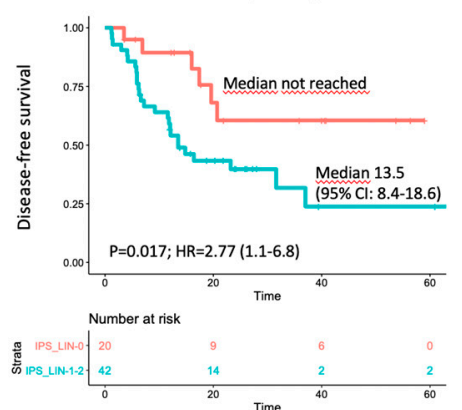
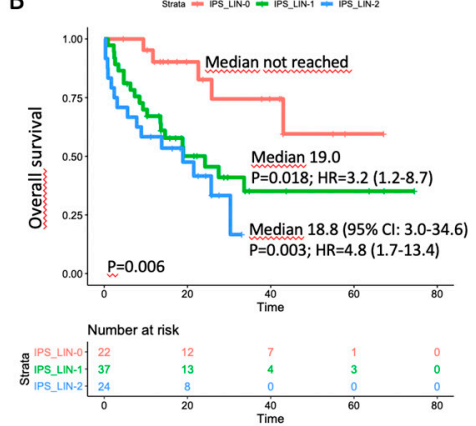

$E$
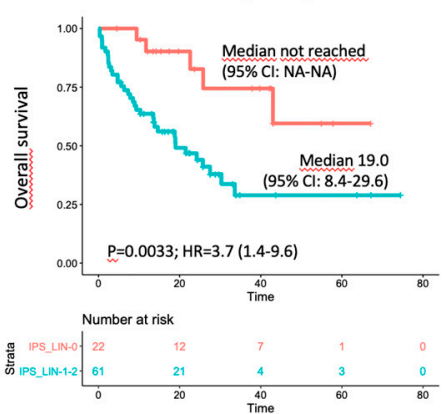
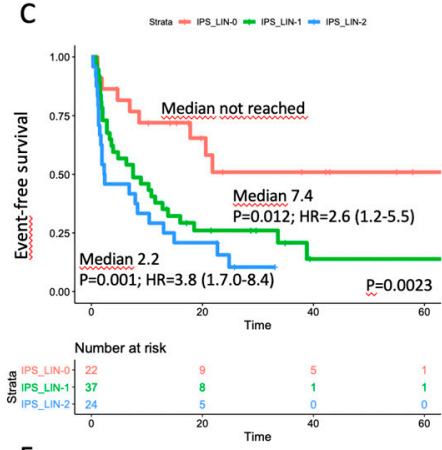

$\mathrm{F}$

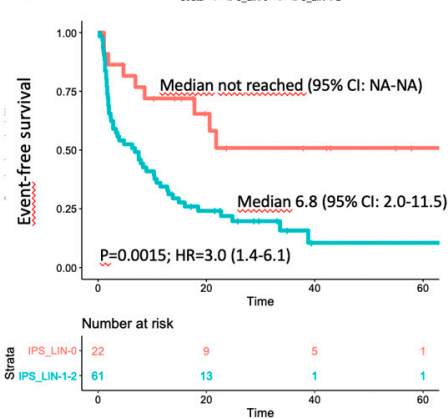

Figure 3. Survival estimates according to IPS in the triple-negative subset. Major outcomes as assessed by Kaplan-Meier curves for (A,D) disease-free survival, $(\mathbf{B}, \mathbf{E})$ overall survival, and (C,F) event-free survival (EFS) according to number of dysplastic lineages by immunophenotypic score (IPS) in triple-negative (TN-AML) patients. In panels (A-C), patients were separated in three categories; in panels D-F, IPS_1 and IPS_2 cases were grouped.

Table 2. Characteristics of patients according to IPS in triple-negative disease subset.

\begin{tabular}{|c|c|c|c|}
\hline & IPS_0 $n=22(26.5 \%)$ & IPS_1-2 $n=61(73.5 \%)$ & $p$ Value \\
\hline Age, median (range) & $56.5(35-72)$ & $56(22-73)$ & 0.958 \\
\hline $\mathrm{WBC}, \times 10^{9} / \mathrm{L}$, median (range) & $2.2(0.6-36.9)$ & $5.7(1.0-220)$ & 0.018 \\
\hline $\mathrm{Hb}, \mathrm{g} / \mathrm{dL}$, median (range) & $9.5(4.8-13.3)$ & $9.0(4.6-14.9)$ & 0.350 \\
\hline Plt, x109/L, median (range) & $72(16-281)$ & $54(3-271)$ & 0.070 \\
\hline \multirow{2}{*}{$\begin{array}{l}\text { Bone marrow blasts, } \% \text {, } \\
\text { median (range) }\end{array}$} & $85(20-100)$ & $80(20-100)$ & 0.910 \\
\hline & Karyotype, n (\%) & & \\
\hline Normal & $11(50.0)$ & $46(75.4)$ & 0.034 \\
\hline Intermediate, non-normal & $8(36.4)$ & $12(19.7)$ & 0.148 \\
\hline Lack of growth & $3(13.6)$ & $3(4.9)$ & 0.186 \\
\hline
\end{tabular}

Differences between treatment groups were evaluated using Kruskal-Wallis test for continuous variables and Fisher exact tests or $\chi^{2}$ for categorical variables. Values in bold are statistically significant $(p<0.05)$. Abbreviations: IPS, Immuno-Phenotypic Score; WBC, white blood cells; Hb, hemoglobin, Plt, platelets. 
Table 3. Multivariate analyses (Cox regression) for major outcomes in triple-negative AML.

\begin{tabular}{|c|c|c|c|c|c|c|c|c|c|c|}
\hline & \multicolumn{10}{|c|}{ MULTIVARIATE ANALYSIS } \\
\hline & HR $(95 \%$ CI) & $p$ & HR $(95 \%$ CI) & $p$ & HR $(95 \%$ CI) & $p$ & HR (95\% CI) & $p$ & $\operatorname{HR}(95 \% \mathrm{CI})$ & $p$ \\
\hline & Step 1 & & Step 2 & & Step 3 & & Step 4 & & Step 5 & \\
\hline \multicolumn{11}{|l|}{ Disease-free survival } \\
\hline Age $(</ \geq 50$ y) & $\begin{array}{c}0.62 \\
(0.25-1.57)\end{array}$ & 0.31 & $\begin{array}{c}0.64 \\
(0.26-1.56)\end{array}$ & 0.33 & $\begin{array}{c}0.65 \\
(0.27-1.58)\end{array}$ & 0.34 & - & - & - & - \\
\hline WBC (cont.) & $\begin{array}{c}1.00 \\
(1.00-1.00)\end{array}$ & 0.19 & $\begin{array}{c}1.00 \\
(1.00-1.00)\end{array}$ & 0.19 & $\begin{array}{c}1.00 \\
(1.00-1.00)\end{array}$ & 0.18 & $\begin{array}{c}1.00 \\
(1.00-1.00)\end{array}$ & 0.21 & - & - \\
\hline Karyotype (normal vs. not) & $\begin{array}{c}1.42 \\
(0.53-3.78)\end{array}$ & 0.48 & $\begin{array}{c}1.32 \\
(0.58-3.03)\end{array}$ & 0.51 & - & - & - & - & - & - \\
\hline Induction (SDAC vs. HDAC) & $\begin{array}{c}0.88 \\
(0.35-2.23)\end{array}$ & 0.79 & - & - & - & - & - & - & - & - \\
\hline HSCT (T-dep.) & $\begin{array}{c}0.18 \\
(0.06-0.52)\end{array}$ & 0.002 & $\begin{array}{c}0.18 \\
(0.06-0.52)\end{array}$ & 0.002 & $\begin{array}{c}0.18 \\
(0.06-0.53)\end{array}$ & 0.002 & $\begin{array}{c}0.22 \\
(0.08-0.59)\end{array}$ & 0.002 & $\begin{array}{c}0.24 \\
(0.09-0.63)\end{array}$ & 0.046 \\
\hline IPS (_0 vs. _1-2) & $\begin{array}{c}3.04 \\
(1.04-8.90)\end{array}$ & 0.042 & $\begin{array}{c}2.89 \\
(1.07-7.80)\end{array}$ & 0.036 & $\begin{array}{c}2.53 \\
(1.01-6.23)\end{array}$ & 0.046 & $\begin{array}{c}2.43 \\
(0.98-6.00)\end{array}$ & 0.046 & $\begin{array}{c}2.21 \\
(0.89-5.45)\end{array}$ & 0.003 \\
\hline \multicolumn{11}{|l|}{ Overall survival } \\
\hline Age $(</ \geq 50$ y) & $\begin{array}{c}0.97 \\
(0.45-2.10)\end{array}$ & 0.95 & - & - & - & - & - & - & - & - \\
\hline WBC (cont.) & $\begin{array}{c}1.00 \\
(1.00-1.00)\end{array}$ & 0.70 & $\begin{array}{c}1.00 \\
(1.00-1.00)\end{array}$ & 0.70 & $\begin{array}{c}1.00 \\
(1.00-1.00)\end{array}$ & 0.73 & - & - & - & - \\
\hline Karyotype (normal vs. not) & $\begin{array}{c}2.07 \\
(0.92-4.63)\end{array}$ & 0.08 & $\begin{array}{c}2.06 \\
(0.93-4.60)\end{array}$ & 0.08 & $\begin{array}{c}1.93 \\
(0.97-3.84)\end{array}$ & 0.06 & $\begin{array}{c}1.94 \\
(0.98-3.86)\end{array}$ & 0.06 & $\begin{array}{c}1.76 \\
(0.91-3.42)\end{array}$ & 0.095 \\
\hline Induction (SDAC vs. HDAC) & $\begin{array}{c}0.87 \\
(0.38-2.00) \\
\end{array}$ & 0.75 & $\begin{array}{c}0.88 \\
(0.40-1.96) \\
\end{array}$ & 0.75 & - & - & - & - & - & - \\
\hline HSCT (T-dep.) & $\begin{array}{c}0.59 \\
(0.25-1.40)\end{array}$ & 0.23 & $\begin{array}{c}0.59 \\
(0.26-1.34)\end{array}$ & 0.21 & $\begin{array}{c}0.58 \\
(0.26-1.29)\end{array}$ & 0.18 & $\begin{array}{c}0.58 \\
(0.26-1.30)\end{array}$ & 0.19 & - & - \\
\hline IPS (_0 vs. _1-2) & $\begin{array}{c}4.95 \\
(1.73-14.1)\end{array}$ & 0.003 & $\begin{array}{c}4.93 \\
(1.74-14.0)\end{array}$ & 0.003 & $\begin{array}{c}4.69 \\
(1.74-12.6)\end{array}$ & 0.002 & $\begin{array}{c}4.60 \\
(1.72-12.3)\end{array}$ & 0.002 & $\begin{array}{c}4.61 \\
(1.74-12.2)\end{array}$ & 0.002 \\
\hline
\end{tabular}


Table 3. Cont.

\begin{tabular}{|c|c|c|c|c|c|c|c|c|c|c|}
\hline & \multicolumn{10}{|c|}{ MULTIVARIATE ANALYSIS } \\
\hline & HR $(95 \%$ CI $)$ & $p$ & HR $(95 \%$ CI $)$ & $p$ & HR $(95 \%$ CI $)$ & $p$ & HR $(95 \%$ CI $)$ & $p$ & HR $(95 \%$ CI $)$ & $p$ \\
\hline & Step 1 & & Step 2 & & Step 3 & & Step 4 & & Step 5 & \\
\hline \multicolumn{11}{|l|}{ Event-free survival } \\
\hline Age $(</ \geq 50$ y) & $\begin{array}{c}0.61 \\
(.33-1.13)\end{array}$ & 0.12 & $\begin{array}{c}0.62 \\
(0.34-1.14)\end{array}$ & 0.12 & $\begin{array}{c}0.66 \\
(0.37-1.18)\end{array}$ & 0.16 & $\begin{array}{c}0.69 \\
(0.39-1.22)\end{array}$ & 0.20 & - & - \\
\hline WBC (cont.) & $\begin{array}{c}1.00 \\
(1.00-1.00)\end{array}$ & 0.34 & $\begin{array}{c}1.00 \\
(1.00-1.00)\end{array}$ & 0.35 & $\begin{array}{c}1.00 \\
(1.00-1.00)\end{array}$ & 0.41 & - & - & - & - \\
\hline Karyotype (normal vs. not) & $\begin{array}{c}1.17 \\
(0.60-2.27)\end{array}$ & 0.65 & - & - & - & - & - & - & - & - \\
\hline Induction (SDAC vs. HDAC) & $\begin{array}{c}0.76 \\
(0.39-1.46)\end{array}$ & 0.41 & $\begin{array}{c}0.81 \\
(0.45-1.47)\end{array}$ & 0.48 & - & - & - & - & - & - \\
\hline HSCT (T-dep.) & $\begin{array}{c}0.21 \\
(0.07-0.60)\end{array}$ & 0.003 & $\begin{array}{c}0.21 \\
(0.08-0.61)\end{array}$ & 0.004 & $\begin{array}{c}0.21 \\
(0.07-0.59)\end{array}$ & 0.003 & $\begin{array}{c}0.22 \\
(0.08-0.61)\end{array}$ & 0.004 & $\begin{array}{c}0.26 \\
(0.09-0.69)\end{array}$ & 0.007 \\
\hline IPS (_0 vs. _1-2) & $\begin{array}{c}2.87 \\
(1.31-6.28)\end{array}$ & 0.009 & $\begin{array}{c}2.69 \\
(1.29-5.58)\end{array}$ & 0.008 & $\begin{array}{c}2.62 \\
(1.27-5.41)\end{array}$ & 0.009 & $\begin{array}{c}2.51 \\
(1.21-5.16)\end{array}$ & 0.013 & $\begin{array}{c}2.50 \\
(1.22-5.14)\end{array}$ & 0.012 \\
\hline
\end{tabular}

In the final step of the multivariate analysis, statistically significant values $(p<0.05)$ are indicated in bold. Abbreviations: HR, Hazard Ratio; CI, Confidence Interval; WBC, white blood cell; cont., as continuous variable; SDAC, standard dose cytarabine; HDAC, high dose cytarabine; HSCT, allogeneic transplant; T-dep, as time-dependent covariate; IPS,

Immuno-Phenotypic Score. 


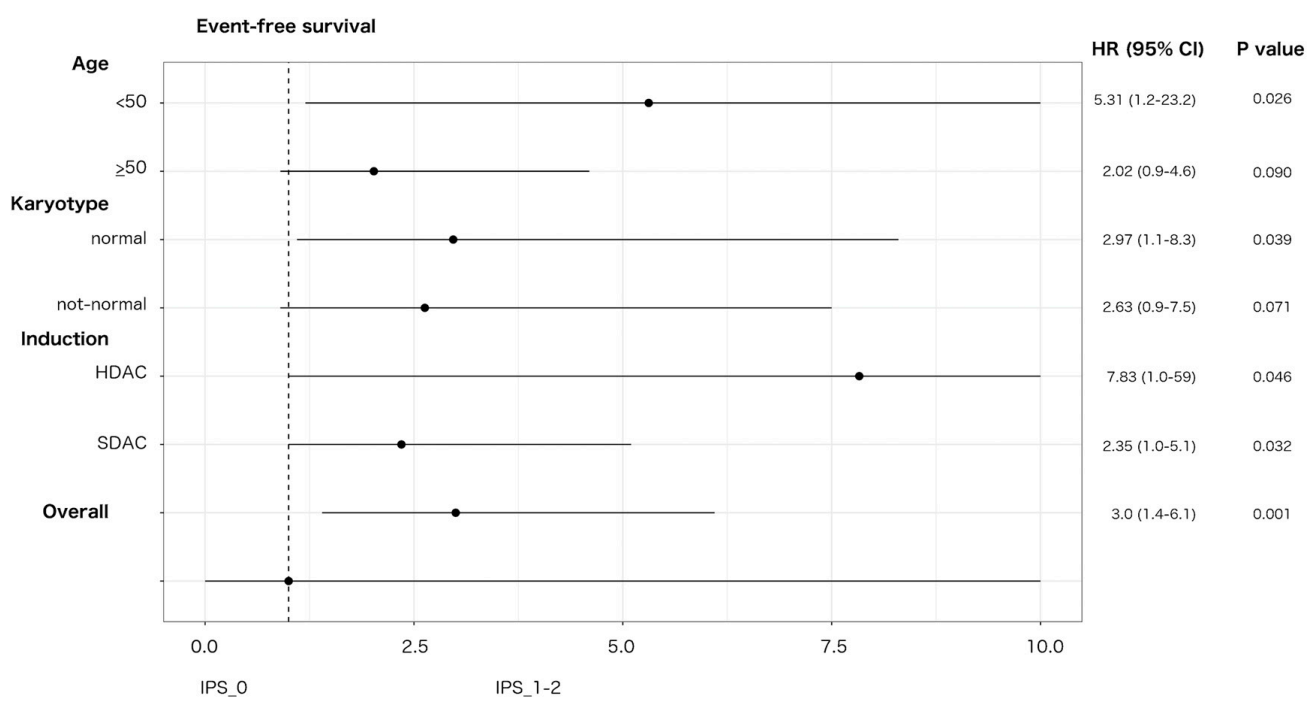

Figure 4. Effect of IPS on EFS in triple-negative AML. Forest plot depicting the effect of IPS-related group (IPS_0 versus IPS_1-2) on EFS in triple-negative AML according to main patient, disease characteristics and induction intensity. $\mathrm{HR}$, hazard ratio; 95\% CI, confidence interval; SDAC: standard-dose cytarabine; HDAC: high-dose cytarabine. Upper 95\% CI HR values were rounded to 10 for sake of graphical resolution.

\subsection{Interaction with Treatment Covariates in TN-AML}

We investigated any potential effect of treatment-dependent covariates (induction containing HDAC versus SDAC; allogeneic HSCT as time-dependent) on outcome in IPS-related groups (Figures S17-S19). As per EFS, IPS_0 patients showed a non-significant trend for a higher impact of HDAC-including induction (HR 0.28; 95\% CI 0.0-2.3; $p=0.23$ ) in comparison with IPS_1-2 (HR 0.92; $95 \%$ CI 0.5-1.6; $p=0.77)$. Both IPS categories had an EFS benefit from allogeneic transplant with HR values of $0.11(p=0.048)$ and $0.34(p=0.054)$ for IPS_0 and IPS_1-2, respectively.

\section{Discussion}

The clinical management of patients with AML is progressively diversifying the therapeutic approaches because of the development of novel agents and the refinement of prognostic stratification driven by an increasing knowledge of the genetic background [26]. In the upfront treatment, the kinase inhibitor Midostaurin has improved long-term outcomes in patients bearing FLT3 mutations [27] and benefit from the addition of Gentuzumab Ozogamicin to conventional chemotherapy was achieved mostly in favorable-risk karyotype [28-31]. Still, a non-negligible fraction of patients places in a genetically undefined category. This subset collects by exclusion a variety of cases with heterogeneous biological and clinical characteristics, which lack specific molecular features either for targeted drugs or for proper risk assessment. According to WHO, some of these cases are classified in the AML-MRC subgroup based on morphologically assessed dysplasia, and are therefore stratified as adverse-risk [2]. Such an attribution, driven by a non-standardized technique, is still debated, especially due to the clinical decisions it would imply $[5,7,9,13]$.

In order to address this issue, we retrospectively studied MLD by means of MFC in a large series of AML patients intensively treated at our Center. The correlation with morphology we observed in the unselected analysis reiterated the capability of the MFC-based approach at highlighting dysplasia in AML. As expected, MLD data provided no insight into prognosis when considered overall (Figure 2) or within well-defined genetic categories (Figures S7-S11). Of interest, IPS-related dysplasia conveyed significant prognostic information when we focused on genetically undefined patients (TN-AML), representing about $25 \%$ of our series. In this context, the lack of dysplastic features (IPS_0) correlated with significantly higher $\mathrm{CR}$ rate and longer survival compared to patients showing dysplasia in one 
(IPS_1) or both (IPS_2) evaluated cell lineages (Figure 3). The impact of IPS category maintained its validity after censoring at allogeneic HSCT and in a multivariate analysis including baseline and treatment-related covariates. With respect to the morphology, the application of MFC may be particularly useful in this setting, primarily overcoming the operator-dependent variability in interpretation of dysplastic cell features, and providing the opportunity for quantification of the extent of deviation from normal. Based on the sensitivity set for the detectability of a cell compartment (i.e., $\geq 0.01 \%$ of global cells), the vast majority of our patients were evaluable for dysplasia. The score we adopted has been explored in the MDS setting [14] and can be relatively easy to derive from standard MFC approaches that are employed at the time of diagnostic workup.

Our results could fit with the need for further information for improving the clinical management of patients with TN-AML. In the induction phase, we did not observe any differential benefit in IPS-defined subgroups deriving from the adoption of standard versus high dose cytarabine. The novel therapeutic agent CPX-351, providing a liposomal encapsulation of cytarabine and daunorubicin at a fixed 5:1 molar ratio, appeared superior to standard " $3+7$ " regimen in AML-MRC [32,33]. An analogous advantage was not highlighted in other AML categories [32] and was not demonstrated in patients for whom MRC is defined by morphologic dysplasia, who were excluded from the phase 3 trial [33]. In this view, a more reliable, MFC-based appraisal of dysplasia might aid at identifying patients that potentially benefit from the adoption of CPX-351, as well as other emerging treatment combinations (i.e., BCL2 inhibitors plus hypomethylating agents) [34], in the scarcity of genetic predictors of response.

As per allogeneic HSCT, as well as other therapeutic implications, we recognize the limits of a retrospective study covering a long time period, with consequent changes in risk assessment and treatment allocation. The worse prognosis that we observed for dysplastic cases (IPS_1-2) within TN-AML might suggest an intensification of post-CR phase, by offering HSCT to these patients. In our study, the actual delivery of the transplant yielded a favorable effect on relapse prevention, independently of stratification according to IPS (Figures S17-S19). This finding is consistent with the data from some retrospective, uncontrolled experiences $[35,36]$ and by donor versus no-donor comparison [37] in the same category of patients (i.e., TN-AML).

Beyond its retrospective design, some limitations of our study were the lack of a validation cohort and all the molecular data needed to align with the 2017 ELN stratification [26]. Based on the latter, a small percentage of TN-AML cases would have been reassigned for disease risk due to gene mutations involving TP53, ASXL1, RUNX1. Since all these genotypes correlate to adverse prognosis, it could reasonably be assumed that the enucleation of such cases would not alter the overall results, and, in particular, the relatively good outcome of the IPS_0 group.

\section{Conclusions}

In our retrospective study of intensively treated AML cases, we demonstrated a significant prognostic effect exerted by dysplasia as assessed by flow cytometry in a subgroup featuring a lack of genetic determinants (TN-AML). In this context, our data could help address the relative unmet needs in terms of risk assessment and treatment strategy, and provide insight into the prediction of response in the rapidly evolving therapeutic scenario of AML.

Supplementary Materials: The following are available online at http://www.mdpi.com/2072-6694/12/11/3196/s1, Method S1: Treatment details; Method S2: Assessment of multi-lineage dysplasia by multiparameter flow cytometry; Figure S1: Outcome according to the induction regimen, either including standard dose cytarabine (SDAC) or high dose cytarabine (HDAC); Figure S2: Distribution of phenotypic scores in single cell lineage (neutrophil or erythroid) according to dysplasia by morphology; Figure S3: Distribution of IPS values according to genotype for NPM1, FLT3 and CEBPA; Figures S4-S6: Outcome according to immunophenotypic score (IPS) in WHO-defined subsets; Figures S7-S11: Outcome according to immunophenotypic score (IPS) in genetically defined subsets; Figures S12 and S13: Outcome according to IPS in triple-negative AML with censoring at allogeneic transplant; Figures S14 and S15: Effect of IPS on outcome in triple-negative AML as depicted by Forest plot; Figure S16: Outcome according multi-lineage dysplasia as assessed by morphology in triple-negative AML; Figures S17-S19: Effect of treatment-related covariates (induction and allogeneic transplant) on outcome in 
IPS-related groups as depicted by Forest plot; Table S1: Characteristics of patients according to induction regimen (SDAC vs. HDAC); Table S2: Characteristics of patients according to immunophenotypic score (IPS).

Author Contributions: F.M. designed and performed the research, analyzed and interpreted the data, and wrote the manuscript. S.B., M.P. performed flow cytometric analysis and collected the data. M.I.B., B.P., R.C. performed flow cytometric analysis. G.G., B.S. collected clinical data. F.P., V.P., L.S., M.Z. performed molecular analysis. F.A. and A.B. interpreted the data and critically reviewed the manuscript. All authors have read and agreed to the published version of the manuscript.

Funding: This work was supported by a grant from the Ministero della Salute (project title "Peripheral blast clearance analysis during induction treatment in patients with acute myeloid leukemia", Bando ricerca finalizzata 2013, project code GR-2013-02358238 to FM), from Legato Zottola, and AIRC 5x1000 call “Metastatic disease: the key unmet need in oncology" to MYNERVA project, \#21267 (MYeloid NEoplasms Research Venture AIRC).

Conflicts of Interest: The authors declare no competing financial interests.

\section{References}

1. Vardiman, J.W.; Thiele, J.; Arber, D.A.; Brunning, R.D.; Borowitz, M.J.; Porwit, A.; Harris, N.; Beau, M.M.; Hellström-Lindberg, E.; Tefferi, A.; et al. The 2008 revision of the World Health Organization (WHO) classification of myeloid neoplasms and acute leukemia: Rationale and important changes. Blood 2009, 114, 937-951. [CrossRef] [PubMed]

2. Arber, D.A.; Orazi, A.; Hasserjian, R.; Thiele, J.; Borowitz, M.J.; Beau, M.M.; Bloomfield, C.D.; Cazzola, M.; Vardiman, J.W. The 2016 revision to the World Health Organization classification of myeloid neoplasms and acute leukemia. Blood 2016, 127, 2391-2405. [CrossRef] [PubMed]

3. Arber, D.A.; Stein, A.S.; Carter, N.H.; Ikle, D.; Forman, S.J.; Slovak, M.L. Prognostic impact of acute myeloid leukemia classification. Importance of detection of recurring cytogenetic abnormalities and multilineage dysplasia on survival. Am. J. Clin. Pathol. 2003, 119, 672-680. [CrossRef] [PubMed]

4. Wandt, H.; Schäkel, U.; Kroschinsky, F.; Prange-Krex, G.; Mohr, B.; Thiede, C.; Pascheberg, U.; Soucek, S.; Schaich, M.; Ehninger, G. MLD according to the WHO classification in AML has no correlation with age and no independent prognostic relevance as analyzed in 1766 patients. Blood 2008, 111, 1855-1861. [CrossRef] [PubMed]

5. Miesner, M.; Haferlach, C.; Bacher, U.; Weiss, T.; Macijewski, K.; Kohlmann, A.; Klein, H.-U.; Dugas, M.; Kern, W.; Schnittger, S.; et al. Multilineage dysplasia (MLD) in acute myeloid leukemia (AML) correlates with MDS-related cytogenetic abnormalities and a prior history of MDS or MDS/MPN but has no independent prognostic relevance: A comparison of 408 cases classified as "AML not otherwise specified" (AML-NOS) or "AML with myelodysplasia-related changes" (AML-MRC). Blood 2010, 116, 2742-2751. [PubMed]

6. Weinberg, O.K.; Seetharam, M.; Ren, L.; Seo, K.; Ma, L.; Merker, J.D.; Gotlib, J.; Zehnder, J.L.; Arber, D.A. Clinical characterization of acute myeloid leukemia with myelodysplasia-related changes as defined by the 2008 WHO classification system. Blood 2009, 113, 1906-1908. [CrossRef] [PubMed]

7. Rozman, M.; Navarro, J.-T.; Arenillas, L.; Aventín, A.; Giménez, T.; Alonso, E.; Perea, G.; Camós, M.; Navarrete, M.; Tuset, E.; et al. Multilineage dysplasia is associated with a poorer prognosis in patients with de novo acute myeloid leukemia with intermediate-risk cytogenetics and wild-type NPM. Ann. Hematol. 2014, 93, 1695-1703. [CrossRef]

8. Falini, B.; Macijewski, K.; Weiss, T.; Bacher, U.; Schnittger, S.; Kern, W.; Kohlmann, A.; Klein, H.-U.U.; Vignetti, M.; Piciocchi, A.; et al. Multilineage dysplasia has no impact on biologic, clinicopathologic, and prognostic features of AML with mutated nucleophosmin (NPM1). Blood 2010, 115, 3776-3786. [CrossRef]

9. Díaz-Beyá, M.; Rozman, M.; Pratcorona, M.; Torrebadell, M.; Camós, M.; Aguilar, J.L.; Esteve, J. The prognostic value of multilineage dysplasia in de novo acute myeloid leukemia patients with intermediate-risk cytogenetics is dependent on NPM1 mutational status. Blood 2010, 116, 6147-6148. [CrossRef]

10. Bacher, U.; Schnittger, S.; Macijewski, K.; Grossmann, V.; Kohlmann, A.; Alpermann, T.; Kowarsch, A.; Nadarajah, N.; Kern, W.; Haferlach, C.; et al. Multilineage dysplasia does not influence prognosis in CEBPA-mutated AML, supporting the WHO proposal to classify these patients as a unique entity. Blood 2012, 119, 4719-4722. [CrossRef] [PubMed]

11. Mannelli, F.; Ponziani, V.; Bonetti, M.; Bencini, S.; Cutini, I.; Gianfaldoni, G.; Scappini, B.; Pancani, F.; Rondelli, T.; Benelli, M.; et al. Multilineage dysplasia as assessed by immunophenotype has no impact on clinical-biological features and outcome of NPM1-mutated acute myeloid leukemia. Exp. Hematol. 2015, 43, 869-879.e22. [CrossRef] 
12. Mannelli, F.; Ponziani, V.; Bencini, S.; Bonetti, M.I.; Benelli, M.; Cutini, I.; Gianfaldoni, G.; Scappini, B.; Pancani, F.; Piccini, M.; et al. CEBPA-double-mutated acute myeloid leukemia displays a unique phenotypic profile: A reliable screening method and insight into biological features. Haematologica 2016, 102, 529-540. [CrossRef] [PubMed]

13. Montalban-Bravo, G.; Kanagal-Shamanna, R.; Class, C.A.; Sasaki, K.; Ravandi, F.; Cortes, J.E.; Daver, N.; Takahashi, K.; Short, N.J.; DiNardo, C.D.; et al. Outcomes of acute myeloid leukemia with myelodysplasia related changes depend on diagnostic criteria and therapy. Am. J. Hematol. 2020, 95, 612-622. [CrossRef] [PubMed]

14. Matarraz, S.; López, A.; Barrena, S.; Fernandez, C.; Jensen, E.; Flores-Montero, J.; Rasillo, A.; Sayagues, J.M.; Sánchez, M.L.; Bárcena, P.; et al. Bone marrow cells from myelodysplastic syndromes show altered immunophenotypic profiles that may contribute to the diagnosis and prognostic stratification of the disease: A pilot study on a series of 56 patients. Cytom. Part B Clin. Cytom. 2010, 78, 154-168. [CrossRef] [PubMed]

15. Van de Loosdrecht, A.A.; Alhan, C.; Béné, M.C.; Porta, M.G.D.; Dräger, A.M.; Feuillard, J.; Font, P.; Germing, U.; Haase, D.; Homburg, C.H.; et al. Standardization of flow cytometry in myelodysplastic syndromes: Report from the first European LeukemiaNet working conference on flow cytometry in myelodysplastic syndromes. Haematologica 2009, 94, 1124-1134. [CrossRef] [PubMed]

16. Ogata, K.; Kishikawa, Y.; Satoh, C.; Tamura, H.; Dan, K.; Hayashi, A. Diagnostic application of flow cytometric characteristics of CD34+ cells in low-grade myelodysplastic syndromes. Blood 2006, 108, 1037-1044. [CrossRef] [PubMed]

17. Porta, M.G.; Picone, C.; Pascutto, C.; Malcovati, L.; Tamura, H.; Handa, H.; Czader, M.; Freeman, S.; Vyas, P.; Porwit, A.; et al. Multicenter validation of a reproducible flow cytometric score for the diagnosis of low-grade myelodysplastic syndromes: Results of a European LeukemiaNET study. Haematologica 2012, 97, 1209-1217. [CrossRef]

18. Mitelman, F. (Ed.) ISCN 1995: An International System for Human Cytogenetic Nomenclature (1995): Recommendations of the International Standing Committee on Human Cytogenetic Nomenclature; Karger Medical and Scientific Publishers: Memphis, TN, USA, 1994.

19. Grimwade, D.; Hills, R.K.; Moorman, A.V.; Walker, H.; Chatters, S.; Goldstone, A.H.; Wheatley, K.; Harrison, C.J.; Burnett, A.K.; Group, N. On behalf of the Refinement of cytogenetic classification in acute myeloid leukemia: Determination of prognostic significance of rare recurring chromosomal abnormalities among 5876 younger adult patients treated in the United Kingdom Medical Research Council trials. Blood 2010, 116, 354-365.

20. Falini, B.; Mecucci, C.; Tiacci, E.; Alcalay, M.; Rosati, R.; Pasqualucci, L.; Starza, R.; Diverio, D.; Colombo, E.; Santucci, A.; et al. Cytoplasmic Nucleophosmin in Acute Myelogenous Leukemia with a Normal Karyotype. N. Engl. J. Med. 2005, 352, 254-266. [CrossRef]

21. Noguera, N.; Ammatuna, E.; Zangrilli, D.; Lavorgna, S.; Divona, M.; Buccisano, F.; Amadori, S.; Mecucci, C.; Falini, B.; Lo-Coco, F. Simultaneous detection of NPM1 and FLT3-ITD mutations by capillary electrophoresis in acute myeloid leukemia. Leukemia 2005, 19, 1479-1482. [CrossRef]

22. Kottaridis, P.; Gale, R.; Frew, M.; Harrison, G.; Langabeer, S.; Belton, A.; Walker, H.; Wheatley, K.; Bowen, D.; Burnett, A.; et al. The presence of a FLT3 internal tandem duplication in patients with acute myeloid leukemia (AML) adds important prognostic information to cytogenetic risk group and response to the first cycle of chemotherapy: Analysis of 854 patients from the United Kingdom Medical Research Council AML 10 and 12 trials. Blood 2001, 98, 1752-1759.

23. Pabst, T.; Mueller, B.U.; Zhang, P.; Radomska, H.S.; Narravula, S.; Schnittger, S.; Behre, G.; Hiddemann, W.; Tenen, D.G. Dominant-negative mutations of CEBPA, encoding CCAAT/enhancer binding protein- $\alpha(\mathrm{C} / \mathrm{EBP} \alpha)$, in acute myeloid leukemia. Nat. Genet. 2001, 27, 263-270. [CrossRef] [PubMed]

24. Cheson, B.D.; Bennett, J.M.; Kopecky, K.J.; Büchner, T.; Willman, C.L.; Estey, E.H.; Schiffer, C.A.; Doehner, H.; Tallman, M.S.; Lister, A.T.; et al. Revised recommendations of the International Working Group for Diagnosis, Standardization of Response Criteria, Treatment Outcomes, and Reporting Standards for Therapeutic Trials in Acute Myeloid Leukemia. J. Clin. Oncol. 2003, 21, 4642-4649. [CrossRef] [PubMed]

25. Döhner, H.; Estey, E.H.; Amadori, S.; Appelbaum, F.R.; Büchner, T.; Burnett, A.K.; Dombret, H.; Fenaux, P.; Grimwade, D.; Larson, R.A.; et al. Diagnosis and management of acute myeloid leukemia in adults: Recommendations from an international expert panel, on behalf of the European LeukemiaNet. Blood 2010, 115, 453-474. [CrossRef] 
26. Döhner, H.; Estey, E.; Grimwade, D.; Amadori, S.; Appelbaum, F.R.; Büchner, T.; Dombret, H.; Ebert, B.L.; Fenaux, P.; Larson, R.A.; et al. Diagnosis and management of AML in adults: 2017 ELN recommendations from an international expert panel. Blood 2017, 129, 424-447. [CrossRef] [PubMed]

27. Stone, R.M.; Mandrekar, S.J.; Sanford, B.L.; Laumann, K.; Geyer, S.; Bloomfield, C.D.; Thiede, C.; Prior, T.W.; Döhner, K.; Marcucci, G.; et al. Midostaurin plus Chemotherapy for Acute Myeloid Leukemia with a FLT3 Mutation. N. Engl. J. Med. 2017, 377, 454-464. [CrossRef] [PubMed]

28. Castaigne, S.; Pautas, C.; Terré, C.; Raffoux, E.; Bordessoule, D.; Bastie, J.-N.; Legrand, O.; Thomas, X.; Turlure, P.; Reman, O.; et al. Effect of gemtuzumab ozogamicin on survival of adult patients with de-novo acute myeloid leukaemia (ALFA-0701): A randomised, open-label, phase 3 study. Lancet 2012, 379, 1508-1516. [CrossRef]

29. Hills, R.K.; Castaigne, S.; Appelbaum, F.R.; Delaunay, J.; Petersdorf, S.; Othus, M.; Estey, E.H.; Dombret, H.; Chevret, S.; Ifrah, N.; et al. Addition of gemtuzumab ozogamicin to induction chemotherapy in adult patients with acute myeloid leukaemia: A meta-analysis of individual patient data from randomised controlled trials. Lancet Oncol. 2014, 15, 986-996. [CrossRef]

30. Burnett, A.K.; Russell, N.H.; Hills, R.K.; Kell, J.; Freeman, S.; Kjeldsen, L.; Hunter, A.E.; Yin, J.; Craddock, C.F.; Dufva, I.H.; et al. Addition of Gemtuzumab Ozogamicin to Induction Chemotherapy Improves Survival in Older Patients with Acute Myeloid Leukemia. J. Clin. Oncol. 2012, 30, 3924-3931. [CrossRef]

31. Petersdorf, S.H.; Kopecky, K.J.; Slovak, M.; Willman, C.; Nevill, T.; Brandwein, J.; Larson, R.A.; Erba, H.P.; Stiff, P.J.; Stuart, R.K.; et al. A phase 3 study of gemtuzumab ozogamicin during induction and postconsolidation therapy in younger patients with acute myeloid leukemia. Blood 2013, 121, 4854-4860. [CrossRef]

32. Lancet, J.E.; Cortes, J.E.; Hogge, D.E.; Tallman, M.S.; Kovacsovics, T.J.; Damon, L.E.; Komrokji, R.; Solomon, S.R.; Kolitz, J.E.; Cooper, M.; et al. Phase 2 trial of CPX-351, a fixed 5:1 molar ratio of cytarabine/daunorubicin, vs cytarabine/daunorubicin in older adults with untreated AML. Blood 2014, 123, 3239-3246. [CrossRef] [PubMed]

33. Lancet, J.E.; Uy, G.L.; Cortes, J.E.; Newell, L.F.; Lin, T.L.; Ritchie, E.K.; Stuart, R.K.; Strickland, S.; Hogge, D.; Solomon, S.R.; et al. CPX-351 (cytarabine and daunorubicin) Liposome for Injection Versus Conventional Cytarabine Plus Daunorubicin in Older Patients With Newly Diagnosed Secondary Acute Myeloid Leukemia. J. Clin. Oncol. 2016, 34, 2684-2692. [CrossRef]

34. DiNardo, C.D.; Jonas, B.A.; Pullarkat, V.; Thirman, M.J.; Garcia, J.S.; Wei, A.H.; Konopleva, M.; Döhner, H.; Letai, A.; Fenaux, P.; et al. Azacitidine and Venetoclax in Previously Untreated Acute Myeloid Leukemia. N. Engl. J. Med. 2020, 383, 617-629. [CrossRef] [PubMed]

35. Ahn, J.-S.; Kim, H.-J.; Kim, Y.-K.; Jung, S.-H.; Yang, D.-H.; Lee, J.-J.; Kim, N.Y.; Choi, S.H.; Jung, C.W.; Jang, J.-H.; et al. Transplant outcomes of the triple-negative NPM1/FLT3-ITD/CEBPA mutation subgroup are equivalent to those of the favourable ELN risk group, but significantly better than the intermediate-I risk group after allogeneic transplant in normal-karyotype AML. Ann. Hematol. 2016, 95, 625-635. [CrossRef] [PubMed]

36. Schmid, C.; Labopin, M.; Socié, G.; Daguindau, E.; Volin, L.; Huynh, A.; Bourhis, J.H.; Milpied, N.; Cornelissen, J.; Chevallier, P.; et al. Outcome of patients with distinct molecular genotypes and cytogenetically normal AML after allogeneic transplantation. Blood 2015, 126, 2062-2069. [CrossRef] [PubMed]

37. Heidrich, K.; Thiede, C.; Schäfer-Eckart, K.; Schmitz, N.; Aulitzky, W.E.; Krämer, A.; Rösler, W.; Hänel, M.; Einsele, H.; Baldus, C.D.; et al. Allogeneic hematopoietic cell transplantation in intermediate risk acute myeloid leukemia negative forFLT3-ITD, NPM1- or biallelic CEBPA mutations. Ann. Oncol. 2017, 28, 2793-2798. [CrossRef] [PubMed]

Publisher's Note: MDPI stays neutral with regard to jurisdictional claims in published maps and institutional affiliations.

(C) 2020 by the authors. Licensee MDPI, Basel, Switzerland. This article is an open access article distributed under the terms and conditions of the Creative Commons Attribution (CC BY) license (http://creativecommons.org/licenses/by/4.0/). 